\title{
THE IMPACT OF ONLINE ACTIVITIES ON STUDENTS' HEALTH AND THE IMPORTANCE OF TIME MANAGEMENT
}

\author{
Carolina Bodea Hațegan ${ }^{1}$, Dorina Talaș ${ }^{2}$, \& Raluca Trifu ${ }^{3}$ \\ ${ }^{1}$ PhD Associate Professor, Department of Special Education, Faculty of Psychology and Education \\ Sciences, Babeș-Bolyai University, Cluj-Napoca, (Romania) \\ ${ }^{2} \mathrm{PhD}$ Associated Lecturer, Department of Special Education, Faculty of Psychology and Education \\ Sciences, Babeș-Bolyai University, Cluj-Napoca, (Romania) \\ ${ }^{3}$ PhD Assistant Professor, Department of Medical Education, University of Medicine and Pharmacy, Iuliu \\ Hațieganu, Cluj-Napoca, (Romania)
}

\begin{abstract}
The aim of this study is to highlight the importance of time management during online activities for students. At the beginning of the pandemic period, on March the 2020, after the first online activity, a pilot study was conducted to identify the students' perception about online activities, the time they should spend online during the day, the time students spend on different devices (computer, tablet or mobile phone) and the difficulties they have during the first online activities. A number of 106 students (44 boys and 62 girls) in 5th grade, from a middle school located in an urban area, in Romania, participated in this study. The results demonstrate that most of the students (33) representing 31.1\% spend $1-2$ hours/day online but there are 6 students $(5.6 \%)$ who spend more than 6 hours/day online. Most of the students (56.6\%) consider they should have 3 online activities/day and the duration of these activities should be 40 - 50 minutes. Strategies to promote students' wellbeing during online activities are also presented focusing on identifying the best way to use the time spend online in order to reach the necessary curricular objectives and to avoid health problems. The conclusions highlight the importance of finding the best time management strategies for online activities to avoid future health problems for students, especially in the situation in which at the global level the pandemic period is not even closed to the end point. As screen time is a controversial factor, with high implication for health and education, data are important for sustainability of educational system and future decisions.
\end{abstract}

Keywords: Time management, online activities, students' wellbeing, IT devices, screen time.

\section{Introduction}

Screen time is a very studied concept especially in this time when children and adults tend to be preoccupied, and in the same time, tend to rely their learning and working experiences on all the instruments that are covered under this concept umbrella: television, smartphones, tablets, computers, laptops, video game consoles, iPads, handheld electronic or gaming devices. Oswald, Rumbold, Kedzior, \& Moore (2020) underline that when defying screen time, the use of the internet, social media, or communicating via text message are all means and activities that are considered as part of this concept while just auditory activities, such as talking on a phone and listening to music, are not included. This concept is related with digital media use and the concept of mental health due to the important implications that spending time on these screen -based devices can have (Stiglic, Viner, 2019).

The green time is the opposite term of screen time and it refers to the time a person spends in a natural environment, walking, working or doing physical exercise and relaxing. The opposition screen vs green time must be reinterpreted, nowadays, in pandemic situations, when the outdoor walking, travelling and other common activities such as visits and holidays are restricted and even forbidden.

A study published in 2012 (Sigman, 2012) indicates that at a rate of 2 hours/day, a child born nowadays, by the age of seven years, will have spent one full year of $24 \mathrm{~h}$ days watching screen media. The same study (Sigman, 2012) calculates that by the age of 18 years, the average European child will have spent 3 years of $24 \mathrm{~h}$ days watching screen media and at this rate, by the age of 80 years, they will have spent 17.6 years on media screens. 
In a study The Centers for Disease Control and Prevention (CDC,2021) reports that children ages eight to 10 spend an average of six hours per day in front of a screen, kids age 11 to 14 spend an average of nine hours per day in front of a screen, and youth ages 15 to 18 spend an average of seven-and-a-half hours per day in front of a screen. Doctors, especially the pediatricians, underline the needs for one rule no screens for children who are under the age of two, and 1 hour/day for children under 5 ( WHO, 2019; APA, 2016; (Guram \& Heinz, 2018)) Common Sense Media support group (2018) indicates specific information about children age 5-7 use the screen time for different reasons - $42 \%$ own their own tablets, $63 \%$ play games online for nearly 7.5 hours, $82 \%$ are online almost 9 hour a week and $70 \%$ use YouTube, watch cartoon and funny video.

The psychological implications related to screen time are in detail described by analyzing specialized literature in the field on three age intervals: young children $(<5$ years $)$, schoolchildren (5-11 years), early adolescents (12-14 years), and older adolescents (15-18 years). The psychological following aspects are related with mental health, cognitive functioning and academic achievement, in the figure below these three dimensions are operationalized. In order to illustrate these aspects, researchers investigated 186 studies that the authors identified in four relevant databases (PubMed, PsycInfo, Scopus, Embase).

Table 1. Psychological implications to be studied related to screen time (according to Oswald, Rumbold, Kedzior, \& Moore, 2020).

\begin{tabular}{|c|c|c|}
\hline Constructs & \multicolumn{2}{|l|}{ Variables } \\
\hline \multirow[t]{2}{*}{ Indieators of Poor Mental Health } & \multicolumn{2}{|c|}{ Common internalising or externalising disorders 2 or their symptoms, buch as: } \\
\hline & $\begin{array}{l}\text { - Depression } \\
\text { - Anxicty } \\
\text { - Stress } \\
\text { - Psychological distress } \\
\text { - Poor self-regulation }\end{array}$ & $\begin{array}{l}\text { - Emotional problems } \\
\text { - Psychological difficultics } \\
\text { - Psychosomatic symptoms } \\
\text { - Negative affect or mood }\end{array}$ \\
\hline Indicators of Positive Mental Health & \multicolumn{2}{|c|}{ Refers to elements of positive psychology or overall well-being, such as: } \\
\hline \multirow[t]{2}{*}{ Cognitive Functioning } & \multicolumn{2}{|c|}{ Refers to mental processes, such as: } \\
\hline & $\begin{array}{l}\text { - Attention } \\
\text { - Working memory } \\
\text { - Executive function }\end{array}$ & - Visual, spatial, verbal, language, and cognitive development \\
\hline
\end{tabular}

hiths:/doi.org/10.1371/joumal.pone.0237725.t001

This article is a very comprehensive and in depth analysis of the specialized literature in the screen time filed, the large number of investigated studies underlying both the fact that research preoccupation in this field is significantly increasing, in direct relation with the increase in the time spent in front of screens during a day, not only in small children but mostly in adolescents and even in adults, and, in the same time, that both negative and positive aspects related with these increase have to be considered as they can lead to significant impact on global development.

Results of the research (Oswald, Rumbold, Kedzior \& Moore, 2020) underlined that the cognitive and behavior disorders in children aged under 5 are correlated with an increased number of hours, more than 2 hours using screens. Among these cognitive am behavior disorders the following are listed: communication disorders, language disorders, effort engagement control, self-regulation and self-control. These results are strengthened by data provided by Stiglic and Viner (2019) Canadian Paediatric Society, 2017 and American Pediatric Society, 2016 that established several regulations in order to help parents limit the children screen time due to the cognitive and health negative implications (obesity and other physical problems). Madigan, Browne, Racine, Mori, Tough, 2019 underline that at this age, screen exposure can influence the children 's global development, obtaining lower results in developmental screening tests.

In school age children, beyond the cognitive and physical problems, researchers underline that the learning outcomes are very much negatively influenced, thus: attention and memory deficits as well as visuo-spatial processing and executive functioning are correlated with learning disorders and increase screen time (Barlett, Gentile, Barlett, Eisenmann, Walsh, 2012; Rosenqvist, Lahti-Nuuttila, Holdnack, Kemp, Laasonen, 2016;Swing, Gentile, Anderson, Walsh, 2010; Stiglic, Viner, 2019; Tremblay, LeBlanc, Kho et al. 2011; Oswald, Rumbold, Kedzior \& Moore, 2020).

In adolescents and older children, beyond the above mentioned cognitive and health problems researchers underline the correlation between screen time and psychological disorders such as: higher 
anxiety symptoms, depression/depressive symptoms, externalizing problems (Cao, Qian, Weng, Yuan, Sun, Wang, et al. 2011; Oswald, Rumbold, Kedzior \& Moore, 2020, Stiglic, Viner, 2019; Babic, Smith, Morgan, Eather, Plotnikoff, Lubans, 2017; Benson, Williams, Novick, 2013).

It is obvious that screen time exposure influences greatly both small children and adolescents, screen time exposure constantly increase, and the type of screen exposure too, if older studies brought into light the negative effects of television on general health and psychological development, the nowadays studies enlarge the screen exposure type a lot and tablets, smartphone and other technological devices are increasingly used. In pandemic time, this increase exposure as well as wider the screen type possibilities were a necessity, their impacts or the way the mandatory facet and the health ensuring are important to be considered both at micro level (by parents and educators), and at macro level (by national and international authorities).

\section{Design}

The research methodology for this study was to identify students' perception about the first online activity, their screen time and the difficulties they identified. This quantitative study involved 106 students (44 boys and 62 girls) in 5th grade (four classes), from a middle school located in an urban area, in Romania at the beginning of SARS-CoV2 pandemic.

\section{Objectives}

The objectives of this research are:

- To identify the students' perception about online activities;

- To determine the student's perception on the time they should spend online during a school day;

- To determine the difficulties students in $5^{\text {th }}$ grade have during the first online activities.

\section{Methods}

A Google Form questionnaire was used to collect data starting from March 19, 2020 to April 02, 2020. The questionnaire was sent to the students using Google Classroom. The first part of the questionnaire contains demographic information about the students, the second part contains information about the devices students use for online activities and about the difficulties they encountered (technical problems or poor internet connection). The third part of the questionnaire contains information about the advantages of online classes, the difficulties they encountered and the feelings they experienced during the first online activity from their life. The last part of the questionnaire was about the time students spend online/day and their perception on the time they should spend online per a day during a class and during a school day.

\section{Results}

Most of the students use a computer or a tablet (69,8\%), 24,5\% students use the phone and only $5,7 \%$ of the students use a tablet. The students encountered the following problems: technical problems $(28,3 \%)$, poor Internet connection $(10,4 \%)$ and $61,3 \%$ declared they did not have any problems.

The advantages and disadvantages identified by the students during the first online activity are presented in table 2, they being similar with those presented by specialized literature (Guram, Heinz, 2018; Bodea Hațegan, Talaș, 2020).

Table 2. Advantages and disadvantages identified by the students during the first online activity.

\begin{tabular}{|l|l|}
\hline \multicolumn{1}{|c|}{ Advantages students identified during online activities } & Disadvantages students identified during online activities \\
\hline -activities are interesting; & -we cannot concentrate because we cannot see our \\
-we can continue our lessons; & teachers face to face; \\
-we pay attention; & -we spend more time in front of the computer; \\
-we can interact with our colleagues and teachers; & -the sound quality is poor sometimes; \\
-we can stay at home and save the time we spend to go to & -poor internet connection; \\
school; & -we do not socialize, lack of interaction between the \\
-it is possible to participate in a class from all over the & students; \\
world; & -excessive screen time; \\
-we are safe; & -communication barriers; \\
-it is simple and comfortable; & -lack of socialization; \\
-we do not have to change classes anymore; & -connection difficulties; \\
-we can sleep longer; & -maybe some children do not have devices; \\
-these online activities change our lifestyle & \\
\hline
\end{tabular}


Some of the students' answers to the question "How did you feel when you first went online with colleagues and the teacher?" are: "I felt good and it was very interesting.", "I felt good and I'm glad to see my colleagues and the teacher again.", "I felt very good when I first went online with colleagues and the teacher because I haven't seen them in a long time and I was happy.", "Interesting and unusual.", "Interesting, captivating.", "I felt a little excited." "I was a little stressed, because it was the first time I used that site", "I was a little excited because I never had online classes again. But in time, I felt great!", "I was a little excited because I never had online classes again. But in time, I felt great!", "I felt good and I was a little surprised.", "A little excited, but happy because I see my colleagues again.", "I felt good and I really prefer online courses.", "Normal.", "Worse", "A little weird, bad.", "Strange”, "Curious, delighted."

The results recorded to the question "How many hours/minutes do you spend on the computer/laptop/tablet per a day?" are: $31.1 \%$ of the students declared they spend 1-2 hours/day in front of the computer/laptop/tablet/phone per a day, 26,41\% spend 30-60 minutes/day, 14,20\% spend 2-3 hours/day, 13,26\% spend 3-4 hours/day, 3,83\% spend 4-5 hours/day, 0,94\% spend 5-6 hours/day, 4,71\% spend 0-30 minutes/day and 5.6\% spend more than 6 hours/day in front of a device.

For the question "How long do you thing an online activity should be?", 42,5\% of the students consider that an online activity should have 40 minutes and the same percent $(42,5 \%)$ of students consider that an online activity should have 50 minutes. Only $12,3 \%$ consider that an online activity should have 30 minutes and 2,8\% chose 60 minutes. The answers for the question "How many online classes/day do you think a student in $5^{\text {th }}$ grade should have?" are: $56.6 \%$ chose 3 classes, 18,9\% chose 2 classes, 11,3\% chose 4 classes, $8,49 \%$ chose 5 classes and 4,7\% chose 1 class. Results are according with data promoted by Canadian Paediatric Society.

\section{Discussion}

Using a computer or a laptop is very important during online activities because during these activities, students must solve different tasks and the number of students using these devices is high $(69,8 \%)$. The majority of the students $(61,3 \%)$ did not have any problem working online, but $28,3 \%$ had some technical problems and $10,4 \%$ had poor Internet connection. The technical problems were probably due to the students lack of IT knowledge because students start the first IT lessons in schools only in $5^{\text {th }}$ grade.

Students are aware of the importance to reduce screen time and they identified the extended screen time as a disadvantage for online activities. They also identified a lot of advantages for online learning. Most of the students spend 1-2 hours/day in front of the computer/laptop/tablet/phone per a day $(31,1 \%)$ but $5.6 \%$ spend more than 6 hours/day in front of a device. The same number of students $(42,5 \%)$ chose 40 minutes and 50 minutes for an online class probably because face to face school classes used to have 50 minutes. Even if the school schedule includes 5 classes/day the majority of students prefer to have less online classes per a day. These results are very encouraging, students are aware of the implications screen time can have on their development and are really interested in being accordingly trained having into consideration the screen time moderation (Sigman, 2012; Stiglic, Viner, 2019).

Results also prove that online school for $5^{\text {th }}$ graders is not so difficult and it can be a valuable option especially in difficult situations as those represented by pandemic context.

\section{Conclusions}

This study reflects the students' opinion related to the first online activity at the beginning of SARS CoV-2 pandemic, when the online activities structure was not defined in Romanian legislation. Changes must come in the educational system; IT classes should start in primary grades and programs for preventing screen dependency must be implemented. Parents and teachers must encourage a healthy and balanced life for children in the context of online education. New studies are recommended in this field.

\section{References}

Babic, M.J., Smith, J.J., Morgan, P.J., Eather, N., Plotnikoff, R.C., Lubans, D.R. (2017). Longitudinal associations between changes in screen-time and mental health outcomes in adolescents. Mental Health and Physical Activity. 2017; 12:124-31.

Barlett, N.D., Gentile, D.A., Barlett, C.P., Eisenmann, J.C., Walsh, D.A. (2012). Sleep as a Mediator of Screen Time Effects on US Children's Health Outcomes. Journal of Children and Media. 2012;6(1):37-50. 
Benson, L.P., Williams, R.J., Novick, M.B. (2013). Pediatric obesity and depression: a cross-sectional analysis of absolute BMI as it relates to children's depression index scores in obese 7- to 17-year-old children. Clin Pediatr (Phila). 2013;52(1):24-9

Bodea Hațegan, C. Talaș, D. (2020). Ghid Practic de Organizare a Activităților Online (Practical Guide for organizing Online Activities), Colecția Terapia Tulburărilor de Limbaj și de comunicare, Cluj-Napoca: Presa Universitară Clujeană.

Browne, D. T., May, S., Hurst-Della Pietra, P., Christakis, D., Asamoah, T., Hale, L., Delrahim-Howlett, K., Emond, J. A., Fiks, A. G., Madigan, S., Prime, H., Perlman, G., Rumpf, H. J., Thompson, D., Uzzo, S., Stapleton, J., Neville, R., \& Media Impact Screening Toolkit Workgroup of Children and Screens: Institute of Digital Media and Child Development (2019). From 'screen time' to the digital level of analysis: protocol for a scoping review of digital media use in children and adolescents. BMJ open, 9(11), e032184. https://doi.org/10.1136/bmjopen-2019-032184

Canadian Paediatric Society DHTFOO. Screen time and young children: Promoting health and development in a digital world. Paediatrics and Child Health 2017; 22:461 77.

Cao, H., Qian, Q., Weng, T., Yuan, C., Sun, Y., Wang, H., et al. (2011). Screen time, physical activity and mental health among urban adolescents in China. Prev Med. 2011;53(4-5):316-20. pmid:21933680

CDC. (2021). Infographics - Screen Time vs. Lean Time | DNPAO | CDC. https://www.cdc.gov/nccdphp/dnpao/multimedia/infographics/getmoving.html

Common Sense Media: Age-Based Media Reviews for Families. (n.d.). Retrieved March 20, 2021, from https://www.commonsensemedia.org/

Guram, S., \& Heinz, P. (2018). Media use in children: American Academy of Pediatrics recommendations 2016. Archives of Disease in Childhood: Education and Practice Edition, 103(2), 99-101. https://doi.org/10.1136/archdischild-2017-312969

Madigan, S., Browne, D., Racine, N., Mori, C., \& Tough, S. (2019). Association Between Screen Time and Children's Performance on a Developmental Screening Test. JAMA pediatrics, 173(3), 244-250. https://doi.org/10.1001/jamapediatrics.2018.5056

Oswald, T. K., Rumbold, A. R., Kedzior, S., \& Moore, V. M. (2020). Psychological impacts of "screen time" and "green time" for children and adolescents: A systematic scoping review. PloS one, 15(9), e0237725. https://doi.org/10.1371/journal.pone.0237725

Rosenqvist, J., Lahti-Nuuttila, P., Holdnack, J., Kemp, S.L., Laasonen, M. (2016). Relationship of TV watching, computer use, and reading to children's neurocognitive functions. Journal of Applied Developmental Psychology. 2016;46:11-21

Sigman, A. (2012). Time for a view on screen time. Archives of Disease in Childhood, 97(11), 935-942. https://doi.org/10.1136/archdischild-2012-302196

Stiglic, N.; Viner, R. M. (2019). Effects of screen time on the health and well-being of children and adolescents: a systematic review of reviews. BMJ Open. 9 (1): e023191. doi:10.1136/bmjopen2018-023191. PMC 6326346. PMID 30606703.

Swing, E.L., Gentile, D.A., Anderson, C.A., Walsh, D.A. (2010). Television and video game exposure and the development of attention problems. Pediatrics. 2010;126(2):214-21. pmid:20603258.

Tremblay, M.S., LeBlanc, A.G., Kho, M.E., et al. (2011). Systematic review of sedentary behaviour and health indicators in school-aged children and youth. Int J Behav Nutr Phys Act 2011; 8:98 $10.1186 / 1479-5868-8-98$

World Health Organization. (2019). Guidelines on physical activity, sedentary behaviour and sleep for children under 5 years of age. World Health Organization. https://apps.who.int/iris/handle/10665/311664. License: CC BY-NC-SA 3.0 IGO 